\title{
A NATUREZA DO CLIMA E O CLIMA DAS ALTERAÇÕES CLIMÁtICAS
}

\author{
ZANGALLI JUNIOR, Paulo César - paulo.zangalli@ufba.br \\ Universidade Federal da Bahia / UFBA
}

\begin{abstract}
RESUMO: O objetivo deste artigo é apresentar uma discussão crítica acerca dos conceitos de mudança e alteração climática. A princípio destaca-se o debate sobre a relação sociedade e natureza e os distintos conceitos de clima associados às correntes da climatologia na geografia. Em seguida faz-se uma associação à como o clima tem sido produzido e incorporado a uma agenda política, econômica e social. Aponta-se que no debate sobre as alterações climáticas e do papel que cabe à Geografia, em especial à Geografia Física Crítica, há uma ressignificação do conceito de mudança (climatic change) para alteração climática (climate change) que são explicadas pela escala. Dessa forma, as alterações climáticas recentes podem ser entendidas como fenômenos climáticos alterados por uma complexa cadeia de ações sociais e naturais iniciadas a partir da revolução industrial e intensificadas no bojo da sociedade capitalista fossilista.
\end{abstract}

PALAVRAS-CHAVE: Capitalismo Climático; Produção da Natureza; Mudanças Climáticas

\section{THE NATURE OF CLIMATE AND THE CLIMATE CONCEPT OF CLIMATE CHANGE}

\begin{abstract}
The objective of this article is to present a critical discussion about the concepts of climate change and climatic change. At first, the debate about the relationship between society and nature and the different concepts of climate associated with the currents of climatology in geography is highlighted. Then, there is an association to how the climate has been produced and incorporated into a political, economic and social agenda. It is pointed out that in the debate on climate change and the role of Geography, especially Critical Physical Geography, there is a re-signification of the concept of climate change (climatic change) that is explained by the scale. In this way, recent climate change can be understood as climatic phenomena altered by a complex chain of social and natural actions initiated from the industrial revolution and intensified inside of fossils' capitalist society.
\end{abstract}

KEYWORDS: Climate Capitalism; Production of Nature; Climate Change

\section{LA NATURALEZA DEL CLIMA Y EL CLIMA DEL CAMBIO CLIMÁTICO}

RESUMEN: El objetivo de este artículo es presentar una discusión crítica acerca de los conceptos de cambio y cambio climático. Al principio se destaca el debate sobre la relación sociedad y naturaleza y los distintos conceptos de clima asociados a las corrientes de la climatología en la geografía. En la continuación se hace una asociación a cómo el clima ha sido producido e incorporado a una agenda política, económica y social. Se señala que en el debate sobre el cambio climático y el papel que corresponde a la Geografía, en especial a la Geografía Física Crítica, hay una resignación del concepto de cambio climático que se explica por la escala. De esta forma, los cambios climáticos recientes pueden ser entendidos como fenómenos climáticos alterados por una compleja cadena de acciones sociales y naturales iniciadas a partir de la revolución industrial e intensificadas en el seno de la sociedad capitalista fosilista.

PALABRAS CLAVE: Capitalismo Climático; Producción de la Naturaleza; Cambios climáticos

\section{INTRODUÇÃO}

Os dados do NASA's Goddard Institute for Space Studies (GISS) mostram que os últimos cinco anos foram os mais quentes já registrados na 
modernidade, sendo 2018 o quarto mais quente com $0.83^{\circ} \mathrm{C}$ acima da média global (COLE, 2019). Ao mesmo tempo, a relação contraditória entre sociedade e natureza é evidenciada pelos impactos deflagrados pelas chuvas intensas em cidades brasileiras ou por ciclones tropicais como o Ibai que deixou Moçambique e Zimbábue em estado de calamidade.

Enquanto as negociações e as ações de Estado são insuficientes para o enfrentamento do problema, estudantes do mundo todo foram às ruas no Fridays for future, movimento que ganhou força depois que Greta Thunberg, uma estudante sueca de dezesseis anos, faltou às aulas para protestar à frente do parlamento do seu país. Enquanto isso, no Brasil, o novo Ministro das Relações Internacionais escreve que "[...] a esquerda sequestrou a causa ambiental e a perverteu até chegar ao paroxismo, nos últimos 20 anos, com a ideologia da mudança climática, o climatismo" (ARAúJO, 2018). Afirmações como estas acirram um debate ideológico que pouco contribui para o campo científico e para o enfrentamento real dos problemas relacionados ao clima.

O último Simpósio Brasileiro de Climatologia Geográfica parece ter resgatado algumas contradições entre as formas de se pensar o Aquecimento Global dentro da Geografia ${ }^{1}$. Dessa forma, uma questão se faz novamente importante: qual o lugar da Geografia no debate das Alterações Climáticas? Como a Climatologia Geográfica pode contribuir na produção de conhecimento acerca do problema? Dessa forma, o objetivo deste artigo é apresentar uma discussão crítica acerca dos conceitos de mudança e alteração climática.

É claro e evidente que as Alterações Climáticas possuem ecos para além da ciência do clima, adentrando a uma agenda política, econômica e social (HULME, 2009). Por isso, no primeiro momento, abordaremos o papel da geografia e da climatologia geográfica na compreensão dos processos e dos fenômenos relacionados ao aquecimento global, buscando elucidar as diferenças conceituais e os eventuais equívocos na compreensão dos conceitos abordados, trata-se da busca em desvelar a natureza do clima.

Em segundo momento, discutiremos como o clima tem sido produzido e apropriado no debate político, econômico e social. É importante que possamos pensar que tipo de clima é este que tratamos nos espaços político e econômico global, pois os conceitos de clima, mudança e alterações climáticas abordados nestes espaços adquirem conteúdos distintos. Essa diferenciação não é fruto do acaso, mas uma produção que transforma qualquer discussão que se coloque como científica no plano ideológico. Não importa mais o que é clima - em suas bases físicas, nem tão pouco o que se configura alterações climáticas, mas sim o constructo de ideia formulada a partir desse princípio. Conforme afirma Hulme (2009, p. 322) a

\footnotetext{
${ }^{1}$ Em trabalhos anteriores, analisando a produção científica acerca do tema, constatamos que a Geografia, enquanto campo científico, era o único que ainda tensionava o papel das alterações causadas pelo homem em escala global (AUTOR, 2015). Àquele momento apresentei essas contradições como uma disputa entre diferentes paradigmas, sendo o Paradigma do Aquecimento Antropogênico e o Paradigma do Aquecimento Natural, mas hoje o momento atual sugere novas abordagens.
} 
[...] ideia de que os seres humanos estão alterando a física do clima do planeta por meio de ações coletivas, uma ideia capturada no complexo linguístico simples 'mudança climática', é uma ideia tão poderosa nos discursos sociais de hoje quanto as ideias de democracia, terrorismo ou nacionalismo.

Trata-se, portanto, de um trabalho que se insere na abordagem da Geografia do Clima (SANT'ANNA NETO, 2001) e que busca um diálogo crítico, atual e necessário com a Geografia Física Crítica (LAVE et al, 2014).

\section{A NATUREZA DO CLIMA}

Considera-se, pelo menos inicialmente, que o conceito de natureza é mutável de acordo com a finalidade ${ }^{2}$, das formas, dos objetivos de nossa conveniência social (CARVALHO, 2003) e, como parte integrante da natureza o conceito de clima também expressa nas causalidades a mesma relação teleológica.

O que se pretende, nesse aspecto, é evidenciar que o conceito de clima é a expressão da materialidade dos diferentes tipos de tempo em sua habitualidade e sua excepcionalidade, o que demanda uma abordagem geográfica que a compreende em sua totalidade.

Para isso é preciso compreender como o clima tem sido compreendido e analisado na geografia, uma vez que, da concepção de Julius Hann até a primeira virada crítica de Max Sorre a forma como a ciência encara o conceito de clima muda e mudou significativamente. A atmosfera deixou de ser considerada de forma estática e passou a ser considerada em sua variabilidade, sobretudo em temos de dinâmica espaço-temporal das leis físicas do movimento. Mas, para além dessas concepções a Geografia Crítica também apresenta outras possibilidades interpretativas.

Para Zavattini e Boin (2013), o estudo dos climas se altera a partir da crítica de Sorre aos conceitos de tempo e clima. Sua preocupação com os processos atmosféricos, ao invés dos estados médios, levou à crítica do que se chamava de uma Climatologia Estática para uma Climatologia Dinâmica. Isso se deu, fundamentalmente, a partir da análise das sucessões e encadeamento dos tipos de tempo em seu ritmo, compreendido em sequências habituais e excepcionais. Em síntese, a compreensão sorreana dos fenômenos atmosféricos partia da gênese dos fenômenos e não apenas do seu estado (ARMOND, 2014).

Na França da década de 1950, Pierre Pédélaborde seguiu os postulados apresentados por Sorre e construiu a concepção de clima como totalidade de tipos de tempo. Ele elaborou, assim, uma classificação sintética das massas de ar em busca da prevalência dos tipos de tempo sobre determinado lugar (ARMOND, 2014).

Já para Monteiro (2001), a atmosfera possui uma dinâmica oscilante e mutante. Para ele, "a mutabilidade constante das condições atmosféricas é movente por excelência, podendo associar-se ao próprio fluir do tempo que

\footnotetext{
${ }^{2}$ Não se trata de pensar uma teleologia da natureza, mas de pensar a finalidade posta à produção da natureza enquanto uma mercadoria pela sociedade capitalista.
} 
escoa, que flui ininterruptamente". Ao contrário de Pédélaborde, que buscava sintetizar os tipos de tempo, Monteiro construiu seus referenciais a partir do ritmo de Sorre; da concepção de clima como teoria e de tempo como fato a partir de Leslie Curry; do hibridismo metodológico de Paul Feyerabend; do conceito de tempo e a filosofia do ritmo em Henri Bergson e Immanuel Kant; da teoria da massa polar, da meteorologia dinâmica advinda da escola escandinava, entre outros (SANT'ANNA NETO, 2001; MONTEIRO, 2001).

Mais recentemente, Sant'Anna Neto (2001, 2001b, 2011, 2013) apresentou uma abordagem que buscava complexificar o clima para além das características físicas. Os elementos do sistema clima vistos a partir da contradição dialética são, ao mesmo tempo, produto e produtor do espaço no modo de produção capitalista, ou seja, "espaços desiguais potencializam os efeitos do clima, que se manifestam, também, de forma desigual. Nesta perspectiva, tem-se que admitir que o clima possa ser interpretado como uma construção social" (SANT'ANNA NETO, 2011, grifo do autor).

Hulme (2015), ao formular sua proposta de clima, aproxima o conceito daquele formulado por Maximillian Sorre (1951) e Carlos Augusto F. Monteiro (1971), pois destaca o conceito de Tempo para explicar o clima. Para ele "[...] o clima simplesmente permite que a humanidade conviva culturalmente com o seu tempo (weather)" (2015, p.177).

Há uma lógica por detrás dessa afirmação. Hulme apresenta a definição para tempo como "a descrição do estado da atmosfera em relação ao vento, temperatura, nebulosidade, umidade, pressão, etc." e continua afirmando que se trata de "uma condição meteorológica instantânea que medida de maneira objetiva e estatisticamente pela média de um período geraria a definição convencional de clima apresentada pela OMM ou IPCC".

Há uma dualidade nessa compreensão que precisa ser explicada. A definição da OMM apresentada por Hulme, o "conjunto flutuante das condições atmosféricas, caracterizado pelos estados e evolução do tempo no curso de um período suficientemente longo (mínimo 30 anos) para um domínio espacial determinado" é significativamente diferente da apresentada por Sorre (1951) "Série dos estados atmosféricos acima de um lugar em sua sucessão habitual" e Monteiro (1971) "tipos de tempo em sequência contínua, com diferentes combinações dos elementos climáticos entre si e, suas (co)relações com outros elementos geográficos".

A diferença crucial reside no fato de que, para a climatologia geográfica de Sorre e Monteiro, o clima é entendido como um processo considerado na definição do conceito, ou seja, a instabilidade, a desordem, a abstração que o clima possui, frente à concretude do tempo atmosférico. O conceito da OMM é estritamente estatístico e matematizado, pois a ideia de evolução amplamente consagrada pela ciência moderna não permite que o clima volte a ser o que foi, ele é uma construção contínua.

Hulme (2009) afirma que considerar o clima a partir do tempo é atribuir elementos culturais e sociais, uma vez que o tempo pode ser sentido, ouvido e expresso. Monteiro (2000) traz essa mesma concepção ao discutir o tempo presente no paradigma do ritmo climático. Dessa forma, o tempo atmosférico é abordado pensando suas similaridades com o tempo cronológico. Ao fazer isso 
fundamenta a diferença crucial entre a compreensão do tempo atmosférico como um processo evolutivo e como uma sucessão habitual entendida no ritmo.

Monteiro recorre à ontologia para discutir o tempo e o ser retomando a obra de Charles Lindberg. Para ele há uma complementaridade entre o tempo (cronológico) e o ser uma vez que ser significa presente e o tempo é quem determinaria o $\mathrm{ser}^{3}$. O tempo aparece de duas maneiras distintas, como uma flecha em que o tempo é linear ou "sequências-de-agoras" e nunca se repete fruto de uma única dimensão como afirma Kant; ou como circular evitando dessa forma a ideia de tempo morto "o que Ihe possibilita a liberdade de abolir o passado e criar o seu futuro, recriando o seu mundo" (MONTEIRO 2000, p.811).

Essa concepção justificaria a terminologia semelhante para o tempo atmosférico, pois considera todo o caráter mutante e oscilante da atmosfera resumindo sua configuração em estados momentâneos. Considerar o clima a partir dessa conceituação é atribuir elementos além da física da atmosfera e da fragmentação da ciência, pois o tempo que exprime o conceito de clima permite a mutabilidade não só dos elementos físicos da atmosfera, mas também da sociedade. ao dizer que:

Monteiro (2000, p.11) transpõe essa concepção para o tempo e o clima

Dizer que o clima de um lugar é o estado médio dos seus elementos sobre este lugar, é filiar-se ao tempo medido. Propor que o clima de um lugar seja visto como a sucessão habitual dos estados atmosféricos sobre aquele lugar é voltar-se ao tempo oportuno, ao tempo vivido. E esta imagem não é específica do nosso caso, mas vincula-se a vários dualismos: forma-conteúdo; estrutura-processo, etc.

A consolidação da teoria crítica de origem marxista e a inserção da perspectiva da produção do espaço na ciência geográfica no Brasil, principalmente na década de 1970, constituíram-se em influências relevantes nos estudos climáticos. A incorporação da dimensão social na interpretação do clima na Geografia fez com que a repercussão dos fenômenos atmosféricos fosse compreendida num espaço que é socialmente produzido de forma desigual de acordo com diferentes agentes sociais. Assim, tratar da gênese dos fenômenos atmosféricos em função das suas repercussões num espaço socialmente produzido dá sentido à proposta da Geografia do Clima formulada por Sant'Anna Neto, (2001).

Se as sociedades pré-capitalistas consideravam o conceito de natureza e, consequentemente, a sociedade e natureza como indissociável, as sociedades

\footnotetext{
${ }^{3}$ A primeira tese central da crítica materialista, que possibilita a compreensão de uma ontologia do ser social e consequentemente a compreensão de uma ontologia da natureza, a partir de Lukács (2012), é a de que as formas de consciência são condicionadas e explicadas pelo ser social e não o contrário. Dessa forma não seria o tempo que determina o ser, mas o ser que produz o tempo. Isso porque outro postulado central da teoria crítica marxista é a de que o ser humano é um ser ativo, é condicionado pelas relações sociais e as transforma, ou seja, o ser social não é uma massa passiva na história nem tão pouco produtos passivos do ambiente natural e social aos quais estão inseridos.
} 
capitalistas rompem com esse pressuposto para se estabelecerem, permeada por uma estrutura de classes sociais e uma relação de dominação do homem sobre a natureza - mas, também, pela produção da natureza - e consequentemente sobre o espaço e o clima.

Numa concepção capitalista da relação entre sociedade e natureza o clima pode ser considerado como 1) atributo de desorganização do espaço por meio das manifestações excepcionais ${ }^{4} 2$ ) insumo no processo produtivo passível de ser otimizada ou minimizada pelo processo de produção 3) como uma mercadoria produzida e consumida de modos distintos devido aos seus diferentes níveis de inserção no processo de mundialização do capital.

O que é preciso enfatizar é que cada corrente teórica epistemológica apresenta uma clara diferenciação do conceito de clima, o que sugere um enfoque geográfico diferente. Grosso modo, enquanto na Climatologia Estática o enfoque é a atmosfera, a Climatologia Geográfica desloca o foco para a interação clima e sociedade - sem perder o rigor da análise do clima integrando a análise do clima à organização do espaço. Já a Geografia do Clima parte da produção do espaço para explicar como ao mesmo tempo o espaço e o clima são produtos/produtores dessa relação entre clima e sociedade.

Uma síntese da produção do conceito de clima pode ser encontrada em Nascimento Jr (2017, p.97-98). O autor lista ao menos quinze definições possíveis para o mesmo conceito ${ }^{5}$ dos quais reproduzo apenas alguns:

Um conjunto dos fenômenos meteorológicos que caracterizam a condição média da atmosfera sobre cada lugar da Terra (HANN, [1882] 1903) ${ }^{6}$;

\section{$[\ldots]$}

Série dos estados atmosféricos acima de um lugar em sua sucessão habitual ${ }^{7}$;

Conjunto flutuante das condições atmosféricas, caracterizado pelos estados e evolução do tempo no curso de um período suficientemente longo (mínimo 30 anos) para um domínio espacial determinado ${ }^{8}$;

\section{$[\ldots]$}

Não como um fator, mas uma teoria que dela tirando proveito, cada investigador implementa uma dada experiência de tempo meteorológico adequada aos seus próprios propósitos ${ }^{9}$;

Observado por meio da análise dos tipos de tempo em sequência contínua, com diferentes combinações dos elementos

\footnotetext{
4 Que em certa medida podem ser consideradas novas formas de habitualidade (ARMOND, 2018)

5 Em uma ordem que parte das concepções físicas da meteorologia/climatologia e chega a concepções em que, para além dos atributos físicos, o clima é entendido também com atributos sociais,

6 HANN, Julius. Handbook of Climatology. New York: The MacMillan Company, 1903

7 SORRE, M. Les fondements de la Géograhie Humaine. Tome Premier: Les fondaments biologiques. Paris: Armand. Colin, 1951

8 HUSCHKE, Ralph E. Glossary of Meteorology,American Meteorological Society, Boston, 1959.

${ }^{9}$ CURRY, Leslie. Climate and economic life. Geographycal Review, v. 42, n. 3, pp. 367-383, 1952
} 
climáticos entre si e, suas (co)relações com outros elementos geográficos (MONTEIRO, 1971);

$[\ldots]$

Variável no espaço e no tempo, cuja tendência nunca é igual de um ano para o outro e nem de década para década ${ }^{10}$

Se suele definir en sentido restringido como el estado promedio del tiempo y, más rigurosamente, como una descripción estadística del tiempo atmosférico en términos de los valores medios y de la variabilidad de lãs magnitudes correspondientes durante períodos que pueden abarcar desde meses hasta millares o millones de años). En un sentido más amplio, el clima es el estado del sistema climático en términos tanto clásicos como Estadísticos" (IPCC, 2007);

$[\ldots]$

Espaços desiguais potencializam os efeitos do clima, que se manifestam, também, de forma desigual. Nesta perspectiva, tem-se que admitir que o clima (urbano) possa ser interpretado como uma construção social (SANT'ANNA NETO, 2011)

"[...] there is important work still to be done on enriching the idea of climate. The argument is that climate as it is imagined and acted upon - needs to be understood, first, culturally. Rather than framing climate as an interconnected global physical system or as a statistical artefact of weather measurements, climate should be understood equally as an idea that takes shape in cultures and can therefore be changed by cultures. Climate has a cultural history, which is interwoven with its physical history" (HULME, 2015)

Consequentemente, as noções que os conceitos de mudança e alteração climática carregam também são expressões dessas contradições e da multiplicidade de conceitos de clima. Por isso, a mudança climática assume uma base física, mas, também, social (envolvendo dimensões culturais, políticas e econômicas), pois antes de ser mudança o conceito é também clima. A pergunta aqui é, como os diferentes conceitos de clima contribuem para distintas interpretações sobre o que é mudança e alteração climática?

Alguns momentos devem ser destacados como importantes para a compreensão dessas questões. Primeiro, a reconstrução climática a partir de documentos históricos e evidências ambientais, principalmente com as publicações de Hubert Lamb (1966); segundo, os avanços das tecnologias de monitoramento do planeta e a tecnologia dos satélites, impulsionados pelo Ano Geofísico (1957-58), trouxeram uma concepção de clima como um sistema interconectado entre atmosfera, hidrosfera, biosfera e criosfera. Essa concepção desloca o foco das escalas regional e local e coloca sobre o conceito de clima, e consequentemente de mudança climática, um entendimento global. Trata-se de um período que propicia o avanço dos métodos neopositivistas na ciência por meio de modelagem do sistema terrestre (HULME, 2015); terceiro, a emergência de uma nova agenda global dos movimentos ambientalistas dos anos de 1960-70 - em 1963, por exemplo, a Fundação de Conservação de Nova

10 CONTI, José Bueno. Considerações sobre as mudanças climáticas globais 
York já apontava para um potencial perigo atmosférico do aumento da concentração de $\mathrm{CO}_{2}$ (HULME, 2015).

Com a criação da OMM em 1966, um documento foi publicado considerando a mudança climática produzida pelo capitalismo. O importante desse documento é que se assume mudanças climáticas no tempo passado. Nesse relatório as propriedades estatísticas de diferentes séries meteorológicas foram discutidas e comparadas. Assim, a mudança climática foi concebida como um conceito usado para abarcar "[...] todas as formas de inconstâncias climáticas, independentemente de sua natureza estatística (ou causas físicas)" (HULME, 2015).

A discussão sobre este conceito tinha uma clara concepção escalar. $\mathrm{Na}$ escala global, a mudança climática era entendida em período que compreendia séculos ou milhares de anos e, com raras exceções, as causas eram destinadas a variáveis naturais. A interferência humana se restringia as escalas regional e local.

Ainda na década de 1970, o periódico científico Climatic Change foi lançado especificamente para o estudo do tema. Desde então, a sua compreensão tem mudado significativamente. A criação do IPCC em 1988 e da Convenção Quadro das Nações Unidas sobre Mudanças Climáticas (UNFCCC) em 1992 contribuíram para a consolidação do tema.

Houve, inclusive, modificação no conceito explicativo dos processos aplicado ao debate. De mudança climática (climatic change) passou-se a dominar o termo "alterações climáticas" (climate change). Na transposição para o debate em território nacional não houve a diferenciação conceitual entre climatic change e climate change e isso pode ser um indicador das contradições expressas no início deste artigo. Isso porque o que a Geografia considera mudança climática enquanto um conceito engloba ambas terminologias. O que devemos entender como "alterações climáticas", portanto, são fenômenos "[...] causados por uma complexa cadeia de ações humanas e naturais, mas também um agente que poderia influenciar um conjunto abrangente de fenômenos imaginativos e materiais" (HULME, 2015, p.2).

Essa imprecisão científica do conceito de alteração climática pode ser melhor entendida com a sucessão dos relatórios do IPCC. No FAR (First Assessment Report) não havia uma definição precisa a respeito do tema e a definição é apresentada como "[...] a mudança climática" ${ }^{11}$ que estamos a tratar neste relatório é a que deverá ocorrer nos próximos cem anos como resultado das atividades humanas" (IPCC, 1990). Com sua projeção no tempo futuro.

No SAR (Second Assessment Report), o conceito foi melhor explicitado e entendido como "[...] flutuações climáticas de natureza global (...) e que incluem efeitos devido às ações humanas (...) e aqueles devidos a causas naturais" (IPCC, 1995, p.56).

No TAR (Third Assessment Report), o conceito recebeu uma definição que passou a vigorar também para o quarto (AR4) e o quinto relatório (AR5) do IPCC. Neste relatório, alterações climáticas são definidas como:

\footnotetext{
11 Tradução oficial do relatório para o Português Brasil. Para a melhor compreensão deste artigo considerar o termo alteração climática.
} 


\begin{abstract}
Variação estatisticamente significativa em qualquer padrão médio do clima ou em sua variabilidade, que persiste por um período prolongado (geralmente décadas ou mais). A alteração climática pode ser causada devido a processos naturais internos ou forças externas, ou a mudanças antropogênicas persistentes na composição da atmosfera ou no uso da terra (IPCC, 2001, p.788).
\end{abstract}

Essa discussão se resolve quando consideramos as questões escalares envolvidas na diferença dos conceitos. Conti (1998) apresenta uma hierarquização das modificações do clima que diferencia alteração de mudança climática. Para ele, mudança climática é aquela que se dá em escala de tempo de milhares a milhões de anos e com causas naturais, como mudança da excentricidade da órbita ou do eixo de inclinação. Da mesma forma, Conti (1988) classifica alteração climática como aquela que ocorre em tempos históricos curtos, provocados pela atividade antrópica. Uma síntese desses conceitos e de sua relação escalar é apresentado na Tabela 1.

Sant'Anna Neto (2013) mostra que a diferença conceitual também é explicada pela escala. Do local (ritmo), ao global (mudança), passando pelo regional (variabilidade). Para ele, a mudança climática é considerada uma escala temporal que sintetizam processos que ocorrem no tempo geológico, com causa puramente naturais. Trata-se, portanto, de uma escala global em que os processos de análise são generalizados.

Tabela 1 - Hierarquização das modificações globais dos climas.

\begin{tabular}{cll}
\hline Termo & \multicolumn{1}{c}{ Duração } & \multicolumn{1}{c}{ Causas Prováveis } \\
\hline $\begin{array}{c}\text { Revolução } \\
\text { Climática }\end{array}$ & $\begin{array}{l}\text { Superior a 10 } \\
\text { milhões de anos }\end{array}$ & $\begin{array}{l}\text { Atividade geotectônica e possíveis } \\
\text { variações polares }\end{array}$ \\
\hline $\begin{array}{c}\text { Mudança } \\
\text { Climática }\end{array}$ & $\begin{array}{l}10 \text { milhões a } \\
100 \text { mil anos }\end{array}$ & $\begin{array}{l}\text { Mudança na órbita de translação e na } \\
\text { inclinação do eixo da terra }\end{array}$ \\
\hline $\begin{array}{c}\text { Flutuação } \\
\text { Climática }\end{array}$ & 100 mil anos a & $\begin{array}{l}\text { Atividades vulcânicas e mudanças na } \\
\text { emissão solar }\end{array}$ \\
\hline $\begin{array}{c}\text { Interação } \\
\text { Climática }\end{array}$ & Inferior a 10 & $\begin{array}{l}\text { Interação atmosfera-oceano } \\
\text { anos }\end{array}$ \\
$\begin{array}{c}\text { Alteração } \\
\text { Climática }\end{array}$ & Muito curta & $\begin{array}{l}\text { Atividade antrópica, urbanização, } \\
\text { desmatamento, armazenamento de } \\
\text { água etc. }\end{array}$ \\
\hline
\end{tabular}

Fonte: Conti, 1998, p.76. Org. Zangalli Jr, 2018

Essa diferença conceitual explica, em parte, por que a maior parte dos estudos da climatologia geográfica optavam por explicar as variações climáticas verificadas nos últimos anos com enfoque na variabilidade natural do clima, questionando algumas vezes a influência do homem no clima na escala global (ZANGALLI JR, 2015). A adoção do conceito de alteração climática, portanto, confere a este problema ambiental uma escala temporal e espacial definida, mas não rígida.

Dessa forma, as alterações climáticas recentes podem ser entendidas como fenômenos climáticos alterados por uma complexa cadeia de ações sociais e naturais iniciadas a partir da revolução industrial e intensificadas no bojo da 
sociedade capitalista fossilista. É, a partir dessa compreensão que a Geografia pode contribuir de modo crítico com o enfrentamento do problema ambiental que se convencionou nomear Aquecimento Global e que hoje circula como crise climática.

\section{O CLIMA DAS ALTERAÇÕES CLIMÁTICAS.}

A virada epistemológica até aqui proposta - e que tem como pressuposto a crítica a partir do materialismo histórico - se assenta na materialidade, na realidade dos fatos para a compreensão do tempo e do clima. Isso implica, fundamentalmente, apreender o movimento que parte da produção do espaço para compreender as alterações climáticas e desta para entender a produção do espaço. Ou seja, partir de premissas reais, dos indivíduos reais, da sua ação e da sua condição de reprodução da vida para a compreensão da realidade histórica social e natural ${ }^{12}$.

Por isso, retomar a contradição entre a teoria do clima e o clima das alterações climáticas demanda a compreensão da totalidade de seu conteúdo, que no nível aparente se manifesta por meio de retornos a concepções de uma natureza primeira, de um clima natural, que novamente separa a sociedade capitalista do problema enunciado, ou seja, a reprodução da dominação e controle da natureza historicamente transposta para o sentido de ordem e moralidade ${ }^{13}$.

Essa concepção de ordem e moralidade que o conceito de clima adquire é aplicada de maneiras distintas na história. O antropólogo Ellsworth Huntington (1922), por exemplo, sugeria um condicionamento do clima como fator decisivo no desenvolvimento das civilizações, o que legitimaria o domínio das sociedades europeias sobre os demais povos (COMMELAS, 2011, p.19).

O clima não assumiria, nesses casos, nenhuma definição estatística ou física, sendo usado de modo unicamente ideológico para legitimar o racismo, a dominação ou o controle de povos e sociedades, pois como afirmava Montesquieu:

Nas regiões frias, por exemplo, as fibras do corpo comprimemse, aumentando a força e a energia do homem, nas regiões quentes ocorre o inverso, e por isso seus habitantes são mais fracos e covardes. O clima frio da Europa é propício para a formação de Estados livres, enquanto a Ásia, mais quente, só os grandes impérios despóticos, como o da China, podem assegurar a estabilidade e a unidade da população "efeminada" e "indolente" (Montesquieu, apud SANT'ANNA NETO, 2001, p.53)

\footnotetext{
12 Compreendendo que a história consiste na real capacidade humana de transformar a sociedade e consequentemente a natureza

${ }^{13} \mathrm{Na}$ atualidade essa concepção retoma uma natureza normativa, ou seja, "a natureza deve ser seguida como norma para evitar os riscos" (FLORIT, 2004, p.16). Essa concepção encerra uma discussão que deve partir da ordem e da desordem. Nesta perspectiva, o combate à desordem ou à poluição se torna um ato de "esforço positivo e criativo de organizar o ambiente" (FLORIT, 2004, P.26). Portanto, qualquer ato que se justifique como proteção ou recuperação da ordem natural é visto como uma atitude legítima e positiva e fundamenta a reprodução capitalista causadora da desordem.
} 
Outro exemplo importante encontra-se na obra de Belfort de Mattos sobre o clima de São Paulo. Segundo Sant'Anna Neto (2001), no artigo "Em defesa do clima de São Paulo" Belfort de Mattos compara o clima de São Paulo ao de Palermo na Itália, descontruindo a tropicalidade do clima paulista, como uma peça de propaganda para sustentar e atrair os colonos Italianos para trabalharem nas fazendas de café. Estatisticamente os climas de ambas as cidades eram semelhantes, tornando, portanto, o clima de São Paulo como um clima 'quase europeu'.

Por isso, é fundamental compreender que, no conceito de alteração climática, as dimensões culturais, políticas, econômicas e sociais devem ser analisadas, independente das bases físicas do conceito. Hulme (2009) organiza os aspectos da dominação do clima no campo das alterações climáticas por meio de quatro mitos ocidentais, mas que congregam metáfora ideológicas em seus conteúdos.

Primeiro, retoma o clima como uma representação da primeira natureza selvagem e ameaçada que precisa, necessariamente, de proteção ou restauração. Essa ideia carrega em si um potencial mobilizador porque confere ao senso comum a concepção de que o clima simboliza a última fronteira de uma natureza natural, por ser, até pouco tempo atrás, a última fronteira pela qual o capitalismo não teria logrado êxito em mercantilizar. Ao mesmo tempo, mobiliza e dicotomiza a relação sociedade e natureza. Nas palavras de Hulme (2009, p.344):

Este mito das mudanças climáticas - que eu chamo de lamento por Éden - afirma que mudando o clima, perdendo a selvageria de um dos últimos locais intocáveis, o Homem acredita que está diminuindo não apenas a si mesmo, mas algo que está além deles $^{14}$.

Segunda dimensão trata da associação entre as alterações climáticas com coisas que as pessoas temem, com a dimensão mais pura do medo. De acordo com Hulme (2009) essa associação ressoa no cotidiano popular, mas também na dimensão política e econômica. A fala de David King, chefe da assessoria científica do Governo do Reino Unido de que "acredita que as alterações climáticas é uma grande ameaça tanto quanto o terrorismo global" ou a redução do problema climático global, expresso pelo novo Ministro Ernesto Araújo, à ameaça comunista, chamando-o de climatismo, são excelentes exemplos dessa concepção ideológica.

Nesse aspecto, clima, terrorismo ou o climatismo justificam práticas políticas e econômicas controversas, tudo em prol da segurança nacional, justificando a ineficiência do Estado frente a um problema tão urgente, pois esvazia o conceito de conteúdo. É notório que em nome do terrorismo global se trava uma guerra pelo controle da produção do petróleo no oriente médio, na Venezuela, no Brasil etc. Da mesma forma, a produção do clima enquanto uma mercadoria, como novo espaço de reprodução do capital se justifica. O mesmo ocorre quando preferimos chamar as alterações climáticas de crise ou emergência climática global. Afinal o que está em crise, o clima ou modo de

\footnotetext{
${ }^{14}$ Tradução do autor
} 
produção que produz as alterações do climai $O$ emprego desses termos se justifica primeiro porque tem fácil conotação com a forma de uma natureza e um clima frágil que precisa de proteção; segundo porque constrói um novo paradigma de um sistema terrestre baseado apenas em modelos climáticos e em projeções não lineares.

O terceiro aspecto ideológico se configura como o mais significativo, pois retoma o aparente domínio e controle da natureza e do clima, possibilitando uma aproximação com a essência do problema. Hulme apresenta ainda uma quarta dimensão ideológica, a dimensão da moral e da ética ${ }^{15}$, no entanto, enfocaremos agora a terceira dimensão por meio da produção da natureza enquanto estratégia de reprodução do capital como questão central.

Sobre isso Hulme (2009) nos apresenta o que chama de "utopias climáticas", que é onde reside uma contradição importante, a de que sob a fase atual do capitalismo não há dominação e controle, mas a produção da natureza como uma estratégia de reprodução do capital. Isso pode ser facilmente compreendido quando pensamos a geoengenharia, ou seja, a ideia de que é exatamente porque somos responsáveis pelas alterações climáticas que precisamos produzir saídas com mais tecnologia. Dessa forma, não se questiona os impactos do modo de produção capitalista - conteúdo desse novo conceito de alteração climática - muito menos o potencial transformador desses impactos enquanto um limite da acumulação capitalista, mas apenas se apresenta saídas que possam mitigar os impactos produzidos.

Soluções como captura e armazenamento de carbono ou a produção de ressurgência de aguas frias para fertilizar algas marinhas e com isso potencializar a captura de carbono da atmosfera pelos oceanos são soluções que demandam novas tecnologias que criarão novas necessidades de produção, o que no atual contexto político e econômico só serão resolvidos no interior do próprio capitalismo.

Por isso, o clima e as alterações climáticas precisam ser entendidos como um problema ambiental passível de solução. Isso coloca o clima num par entre problema/solução e propicia com que essa concepção, essa ideia seja apropriada e produzida pelo capital já que as soluções são, em sua maioria soluções técnicas no interior daquilo que convencionamos chamar de capitalismo climático ${ }^{16}$.

É fundamental compreender que todos os seres produzem natureza, mas a maneira como os seres humanos produzem natureza se dá de maneira histórica e consciente. Portanto, pode-se escolher os rumos que essa produção terá (MILLAR e MITCHELL, 2015). Os cenários utilizados para a simulação do clima global podem e devem ser interpretados enquanto uma forma de produção da natureza, conforme podemos verificar na Figura 1.

Utilizando apenas dois cenários como referência, é possível destacar algumas palavras-chaves e conceitos importantes que revelam bem 0 movimento que transpõe a dimensão aparentemente ideológica para a produção

\footnotetext{
15 Esse aspecto retoma o diálogo com a dimensão da ordem e desordem

${ }^{16}$ Newell e Paterson (2010) o define como "um modelo que condiciona a necessidade do capitalismo de continuar o crescimento econômico com mudanças substanciais em relação ao desenvolvimento industrial baseado no carbono" o que implicaria uma mudança do sistema econômico em escala global e por isso se configura como um segundo e mais sutil tipo de negação do aquecimento global.
} 
do clima no capitalismo climático. Não há destaque na figura ou nos cenários ao clima em específico, mas sim na forma de produção da natureza. No cenário A2, por exemplo, destacam-se: autossuficiência; preservação das identidades locais; aumento crescente da população; desenvolvimento tecnológico lento e mercado voltado para o regional. No cenário B2 destacam-se: soluções locais; sustentabilidade econômica, social e ambiental; população crescente a níveis mais lentos; proteção ambiental; equidade social, foco no local e regional.

Tanto no cenário mais pessimista (A2), quanto no mais otimista (B2) apresentam-se saídas via 'desenvolvimento tecnológico' bem como 0 crescimento demográfico e um possível controle de natalidade mais rígido. A equidade social e a proteção ambiental se tornam um caminho mais eficiente para o combate às alterações climáticas, segundo o cenário B2. Ou seja, tratase de cenários políticos, econômicos e sociais, mas também climáticos. O que está em jogo, portanto não é a proteção do sistema climático, mas a mudança ou não do padrão de desenvolvimento capitalista consolidado ao longo do tempo.

Os Cenários de Emissões do Relatório Especial sobre Cenários de Emissões (RECE) do $\mathrm{IPCC}^{17}$

A1. O contexto e a família de cenários A1 descrevem um mundo futuro de crescimento econômico muito rápido, com a população global atingindo um pico em meados do século e declinando em seguida e a rápida introdução de tecnologias novas e mais eficientes. As principais questões subjacentes são a convergência entre as regiões, a capacitação e o aumento das interações culturais e sociais, com uma redução substancial das diferenças regionais na renda per capita. A familia de cenários Al se desdobra em três grupos que descrevem direções alternativas da mudança tecnológica no sistema energético. Os três grupos A1 distinguem-se por sua ênfase tecnológica: intensiva no uso de combustiveis fósseis (A1FI), fontes energéticas não-fósseis (A1T) ou um equilíbrio entre todas as fontes (A1B) (em que o equilíbrio é definido como não se depender muito de uma determinada fonte de energia, supondo-se que taxas similares de aperfeiçoamento apliquem-se a todas as tecnologias de oferta de energia e uso final).

A2. O contexto e a família de cenários A2 descrevem um mundo muito heterogêneo. O tema subjacente é a auto-suficiência e a preservação das identidades locais. Os padrões de fertilidade entre as regiões convergem muito lentamente, o que acarreta um aumento crescente da população. $O$ desenvolvimento econômico é orientado primeiramente para a região, sendo que o crescimento econômico per capita e a mudança tecnológica são mais fragmentados e mais lentos do que nos outros contextos.

B1. O contexto e a família de cenários B1 descrevem um mundo convergente com a mesma população global, que atinge o pico em meados do século e declina em seguida, como no contexto $\mathrm{A} 1$, mas com uma mudança rápida nas estruturas econômicas em direção a uma economia de serviços e informações, com reduções da intensidade material e a introdução de tecnologias limpas e eficientes em relação ao uso dos recursos. A ênfase está nas soluções globais para a sustentabilidade econômica, social e ambiental, inclusive a melhoria da eqüidade, mas sem iniciativas adicionais relacionadas com o clima.

B2. O contexto e família de cenários B2 descrevem um mundo em que a ênfase está nas soluções locais para a sustentabilidade econômica, social e ambiental. É um mundo em que a população global aumenta continuamente, a uma taxa inferior à do $\mathrm{A} 2$, com níveis intermediários de desenvolvimento econômico e mudança tecnológica menos rápida e mais diversa do que nos contextos $\mathrm{B} 1$ e A1. O cenário também está orientado para a proteção ambiental e a eqüidade social, mas seu foco são os níveis local e regional.

Um cenário ilustrativo foi escolhido para cada um dos seis grupos de cenários A1B, A1FI, $\mathrm{A} 1 \mathrm{~T}, \mathrm{~A} 2, \mathrm{~B} 1 \mathrm{e} \mathrm{B} 2$. Todos devem ser considerados igualmente consistentes.

Os cenários do RECE não envolvem iniciativas adicionais em relação ao clima, o que significa que nenhum cenário adota explicitamente a implementação da Convenção-Quadro das Nações Unidas sobre Mudança do Clima ou as metas de redução de emissões do Protocolo de Quioto. 
Figura 1 - Classificação dos cenários climáticos do Relatório Especial sobre Cenários de Emissões do IPCC. Fonte: IPCC, 2007.

A inseparabilidade da produção e do controle dos fluxos de matéria e energia e fluxos de capitais é fundamental para compreender o desenvolvimento da sociedade que se funda no modo de produção capitalista que separa e se diz superar o conceito de natureza. Porém, é exatamente esse processo que escapa ao domínio do homem e se conforma em problemas.

Revela-se o que a sociedade moderna tenta realizar e teima em ignorar: que a cultura não exclui a natureza, mas se desenvolve no interior dela, realizando novas sínteses de matéria e energia socialmente instituídas e, portanto, passíveis de novos caminhos, novas agriculturas, novas formas de mediação entre o homem e o seu outro orgânico-inorgânico" (GONÇALVES, 1989, p. 92).

Mas, o sistema climático é encarado em sentido oposto ao sugerido até aqui, pois a atividade humana é entendida como mais uma variável - forçante externa - desprovida de consciência, uma entidade, um objeto desprovido de história ou motivos políticos. Isto implica em um quadro em que a atividade humana responda a alterações climáticas por meio da adaptação ou da geoengenharia, por isso a concepção de natureza sem a política, desconsiderando que a produção da natureza pelo homem se dá de modo histórico e consciente, deve ser considerado uma contradição (SMITH, 2007).

Não há nada de antinatural no processo de modificação do ambiente para a própria reprodução das espécies, incluindo a humana (HARVEY, 2010, p.85). Mas, não há, necessariamente, nada de natural em um modo de produção que demanda constante crescimento e reprodução em uma escala tão grande (MARX, 2011) - incluindo nessa escala o tempo e espaço.

Portanto, encarar as alterações climáticas recentes é, necessariamente, compreender que a natureza do conceito de clima não é natural, mas sim produzido pela sociedade em determinados contextos históricos sobre determinados meios de produção. É compreender que para além de uma média estatística, o clima possui dimensões sociais, políticas, econômicas e culturais que se diferem no tempo e no espaço.

Logo, as alterações climáticas recentes não significam apenas um incremento significativo da concentração de $\mathrm{CO} 2$ e outros GEE, significam considerar que "[...] o aquecimento global [alterações climáticas] é produzido e internalizado ao modo de produção capitalista, não externo e, portanto, a tarefa não é projetar os efeitos da produção, mas reformular totalmente o modelo de produção" (MILLAR and MITCHEL, 2015, p.12). Em síntese, a relação sociedade e natureza entendida de modo dicotômico é fruto de um processo histórico que se consolida com o modo de produção capitalista que entende a natureza enquanto um recurso. 


\section{CONCLUSÕES}

A alteração climática recente foi a peça final para o que alguns cientistas consideram ser uma era geológica marcada pela interferência humana na natureza, ou marcada pela produção da natureza pelo modelo de produção capitalista. O Antropoceno e o capitoloceno são fundamentados na significativa aceleração do tempo, ou seja, a sobreposição do tempo do modo de produção ao tempo da natureza.

Essa associação com o Antropoceno permite algumas conclusões. Primeiro que reafirma o caráter escalar essencial para a compreensão do clima. Dimensão escalar expressa na crítica sorreana do conceito de tempo e clima tão utilizados pela Climatologia Geográfica bem como na relação entre sociedadeclima da Geografia do Clima.

É a dimensão escalar, reafirma-se, que possibilita avançar no debate sobre as alterações climáticas e indicar o papel que cabe à Geografia, em especial à Geografia Física crítica, pois entendido como alteração climática (climate change) e não mais como mudança climática stricto senso (climatic change) que o conceito readquire potencial explicativo para a geografia. Dessa forma, as alterações climáticas recentes podem ser entendidas como fenômenos climáticos alterados por uma complexa cadeia de ações sociais e naturais iniciadas a partir da revolução industrial e intensificadas no bojo da sociedade capitalista fossilista.

Essa definição compreende que a análise deve partir da produção da natureza (e do espaço) para compreender o clima, o que congrega as dimensões científicas, sociais, políticas e econômicas.

Num movimento contraditório, ao mesmo tempo em que possibilita o diálogo com o antropoceno serve de base crítica, uma vez que o Homem não pode ser compreendido como mais uma variável do sistema terrestre, mas sim como sujeitos que produzem a natureza de modo desigual e dicotômico, reproduzindo e reforçando as desigualdades sociais inerentes a uma sociedade de classe.

Por fim, a contribuição da climatologia e da geografia ao debate parte fundamentalmente da perspectiva crítica, compreendendo que o aquecimento global é um problema ambiental criado por e pelo modo capitalista fossilista de produção, se configuram como mais um limite à reprodução ampliada do capital e a sua resolução precisa ser fundamentalmente a superação da essência do problema - o próprio modo de produção.

\section{REFERÊNCIAS BIBLIOGRÁFICAS}

ARAÚJO, E. Sequestrar e Perverter. Disponível em: https://www.metapoliticabrasil.com/blog/sequestrar-e-perverter. Acesso em: $14 / 04 / 2019$

ARMOND, N. B. Entre Eventos e Episódios: as excepcionalidades das chuvas e os alagamentos no espaço urbano do Rio de Janeiro. Dissertação (mestrado) Universidade Estadual Paulista, Faculdade de Ciências e Tecnologia, 2014. Presidente Prudente. 2014. 
ARMOND, N. B. SANT'ANNA NETO, J. L. Entre Eventos e Episódios: ritmo climático e excepcionalidade para uma abordagem geográfica do clima no município do Rio De Janeiro. Revista Brasileira de Climatologia, ano 13, vol. 20, p. 5-28, jan/jul, 2017

ARMOND, N. B. Dinâmica climática, excepcionalidades e vulnerabilidade: contribuições para uma classificação geográfica do clima do estado do Rio de Janeiro. Tese (Doutorado) - Universidade Estadual Paulista, Faculdade de Ciências e Tecnologia, 2018. Presidente Prudente. 2018.

CARVALHO, M. O que é Natureza. São Paulo: Brasiliense, 2003.

COLE, Steve. 2018 Fourth Warmest Year in Continued Warming Trend, According to NASA, NOAA. NASA news release 19-002, 2019. Disponível em: https://www.nasa.gov/press-release/2018-fourth-warmest-year-in-continuedwarming-trend-according-to-nasa-noaa. Acesso em: 14/104/2019.

COMELLAS, J. L. Historia de los cambios climáticos. Madrid: Rialp, 2011.

CONTI, J. B. Clima e Meio Ambiente. São Paulo: Atual Didático, 1998.

FLORIT, L. A Reinvenção Social do Natural. Blumenau: EDIFURB, 2004.

GONÇALVES, Carlos Walter Porto. Os (des) caminhos do meio ambiente. Editora contexto, 1989.

HARVEY, D. Condição pós-moderna: Não há nada de antinatural no processo de modificação do ambiente para a própria reprodução das espécies, incluindo a humana. São Paulo: Loyola, 2010.

HULME, M. Why we disagree about climate change: understanding controversy inaction and opportunity. Cambridge: Cambridge University Press, 2009.

HULME, M. Climate and its changes: a cultural appraisal. Geo: Geography and Environment, v. 2, n. 1, p. 1-11, 2015.

HUNTINGTON, Ellsworth. Civilization and climate. Yale University Press, 1922.

IPCC. Climate Change: The IPCC Scientific Assessment. Cambridge Univeristy Press. cambridge. 1990.

IPCC. Climate Change: IPCC Second Assessment. Cambridge University Press. Cambridge. 1995.

IPCC. Third Assessment Report: Climate Change 2001. Cambridge University Press. Cambridge. 2001.

IPCC. Fourth assessment report (AR4). Climate change, 2007. Cambridge University Press. Cambridge. 2007.

Lamb, Hubert H. Climate in the 1960s. The Geographical Journal, 132, p.183212, 1966.

LAVE, Rebecca. Intervenção: Geografia Física Crítica. Espaço Aberto, PPGG UFRJ, Rio de Janeiro, V. 9, N.1, p. 77-94, 2019

LUKÁCS, György et al. Para uma ontologia do ser social I. São Paulo: Boitempo, 2012.

MARX, K. Grundrisse: manuscritos econômicos de 1857 - 1858: esboços da crítica da economia política. São Paulo: Boitempo, 2011. 
MILLAR, S. W. S.; MITCHELL, D. The Tight Dialectic: The Anthropocene and the Capitalist Production of Nature. Antipode, 2015. 1-19.

MONTEIRO, C. A. de F. De tempos e ritmos: entre o cronológico e o meteorológico para a compreensão geográfica dos climas. Geografia, Rio Claro, 26, n. 3, 2000. 131-154.

MONTEIRO, C. A. de F. De tempos e ritmos: entre o cronológico e o meteorológico para a compreensão geográfica dos climas. Geografia, Rio Claro, v. 26, n. 3, p. 131-154, 2001.

MONTEIRO, Carlos Augusto F. Análise rítmica em Climatologia: problemas da atualidade climática em São Paulo e achegas para um programa de trabalho. Série Climatologia. São Paulo: Instituto de Geografia/USP, 1971

NASCIMENTO JUNIOR, L. Perspectivas da Variabilidade Climática. Geografia em Questão, v. 10, n. 1, p. 95-114, 2017.

NEWELL, P.; PATERSON, M. Climate Capitalism: global warming and the transformation of the global economy. Cambridge: Cambridge University Press, 2010

SANT'ANNA NETO, J. L. História da Climatologia no Brasil: gênese e paradigmas do clima como fenômeno geográfico. Tese (Livre Docência) Faculdade de Ciência e Tecnologia, UNESP. Presidente Prudente. 2001.

SANT'ANNA NETO, J. L. Por uma Geografia do Clima. Terra Livre, São Paulo, v. 17 , p. 49-62, 2001b.

SANT'ANNA NETO, J. L. O clima urbano como construção social: da vulnerabilidade polissêmica das cidades enfermas ao sofisma utópico das cidades saudáveis. Revista Brasileira de Climatologia, v. 8, 2011.

SANT'ANNA NETO, J. L. Escalas geográficas do clima: mudança, variabilidade e ritmo. In: AMORIM, M. C. D. C. T.; NETO, J. L. S.; MONTEIRO, A. Climatologia Urbana e Regional: questões teóricas e estudos de caso. São Paulo: Outras Expressões, 2013.

SMITH, N. Nature as Accumulation Strategy. Socialist Register, v. 43, p. 16-36, 2007.

SORRE, M. Les Fondements de la Géographis Humaine. Tome I - Les Fondements Biologiques - Chap. 5 - Le Climat. Paris: Armound Colin, 1951.

ZANGALLI JR, Paulo C. Entre a Ciência, a Mídia e a Sala de Aula: contribuições da geografia para o discurso das mudanças climáticas. São Paulo: Cultura Acadêmica, 2015.

ZANGALLI JR, Paulo C. O Capitalismo climático como espaço de reprodução do capital: governança do clima e sujeitos sociais. Tese (Doutorado) Universidade Estadual Paulista, Faculdade de Ciências e Tecnologia, 2018. Presidente Prudente. 2018

ZAVATTINI, J. A.; BOIN, M. N. Climatologia Geográfica: teoria e prática de pesquisa. Campinas: Alínea, 2013. 